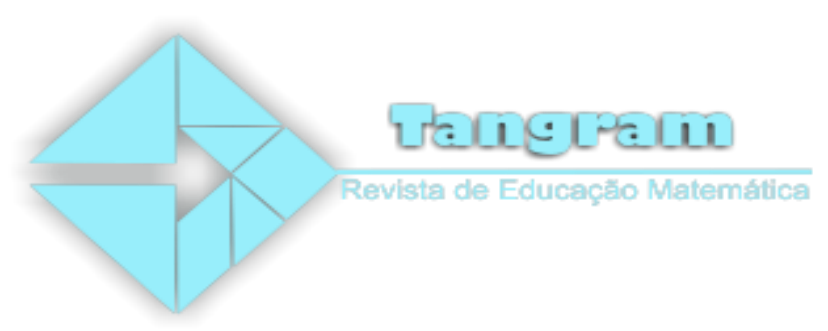

\title{
Análise bibliométrica dos relatos de experiência sobre "Matemática na Educação Infantil" publicados no SHIAM (2013-2017)
}

\section{Bibliometric analysis of experience reports on "Mathematics in Early Childhood Education" published in SHIAM (2013-2017)}

\author{
Klinger Teodoro Ciríaco ${ }^{1}$ \\ Margarida Maria Silva Arantes ${ }^{2}$
}

\begin{abstract}
Resumo: Apresentamos resultados de uma pesquisa que objetivou analisar a produção do conhecimento, em relatos de experiências, sobre a Matemática na Educação Infantil. A base de dados central foi o Seminário Nacional de História e Investigação de/em Aulas de Matemática - SHIAM em que localizamos artigos publicados nos anais das edições de 2013, 2015 e 2017. O referencial teórico-metodológico abrange discussões sobre o que se ensinar "de" e "sobre" Matemática na infância conjugado com um estudo bibliométrico. A análise dos dados revela que a maior parte das atividades desenvolvidas com a criança pequena são destinadas ao trabalho no campo numérico e com destaques para as turmas do jardim de infância, negando assim as possibilidades de promover o pensamento matemático desde a creche. Com o término da investigação, concluímos que é preciso investir em pesquisas e trabalhos formativos, em nível contínuo, com professores que ensinam Matemática desde o trabalho com bebês.
\end{abstract}

Palavras-chave: Matemática na Educação Infantil. Relatos de Experiência. Análise Bibliométrica.

Abstract: We present results of a research that aimed to analyze the production of knowledge, in reports of experiences, about Mathematics in Early Childhood Education. The central database was the National Seminar on History and Research of / in Mathematics Classes - SHIAM - in which we found articles published in the annals of the editions of 2013, 2015 and 2017. The theoretical and methodological framework includes discussions on what to teach "from" and "about" Mathematics in childhood combined with a bibliometric study. The analysis of the data reveals that most of the activities developed with the young child are aimed at work in the numerical field and with highlights for the kindergarten classes, thus denying the possibilities of promoting mathematical thinking from the daycare center. With the end of the investigation, we concluded that it is necessary to invest in research and training work, on a continuous level, with teachers who teach mathematics since working with babies.

Keywords: Mathematics in Early Childhood Education. Experience reports. Bibliometric Analysis.

\section{Fincando estacas: introduzindo a temática}

\footnotetext{
${ }^{1}$ Professor Adjunto do Departamento de Teorias e Práticas Pedagógicas - DTPP - UFSCar; Docente Permanente do Programa de Pós-Graduação em Educação Matemática da Universidade Federal de Mato Grosso do Sul - UFMS - Brasil, ciriacoklinger@gmail.com

${ }^{2}$ Licenciada em Pedagogia pela Universidade Federal de Mato Grosso do Sul - UFMS, Câmpus Naviraí. Professora de Educação Infantil na rede particular de ensino de Naviraí-MS- Brasil, margah.arantes1977@gmail.com
}

Tangram - Revista de Educação Matemática, Dourados - MS - v3 n1, pp. 18-45 (2020) 


\section{Análise bibliométrica dos relatos de experiência sobre "Matemática na Educação Infantil" publicados no SHIAM (2013-2017)}

O trabalho se estrutura a partir de uma pesquisa em que objetivamos analisar a produção do conhecimento em relatos de experiências sobre a presença da Matemática na Educação Infantil. Para este fim, recorremos aos artigos publicados nos anais das edições do Seminário Nacional de História e Investigação de/em Aulas de Matemática - SHIAM - que é um evento nacional de grande visibilidade no que se refere à Educação Matemática, promovido pela Universidade Estadual de Campinas - UNICAMP.

A delimitação para escolha do referido congresso ${ }^{3}$ diz respeito ao fato de que este, à primeira vista, dá destaque às práticas e experiências profissionais dos professores por meio do incentivo para a divulgação das histórias cotidianas presentes mas instituições escolares.

Com a realização deste estudo, busca-se, para além do levantamento e identificação da produção acadêmica, catalogar quais conteúdos matemáticos são predominantes na abordagem da escrita dos relatos, uma vez que, partimos do pressuposto de que esse diagnóstico poderá fornecer pistas para analisar a natureza das atividades matemáticas propostas no período que compreende a infância, bem como o trabalho do professor. Para isso, revisitar as edições será um ponto central na perspectiva de realizar um trabalho de cunho exploratório e de aproximação com artigos "de" e "sobre" Matemática na Educação Infantil.

A pesquisa documental deu-se a partir do mapeamento das publicações com fins de aprofundarmos no assunto e apresentação das intervenções realizadas com crianças de 0 a 5 anos. O marco para a delimitação desta proposta enquadra-se nas três últimas edições do SHIAM (2013, 2015 e 2017), justamente por compreendermos que nos últimos anos a Matemática tem sido objeto de intensas discussões na tentativa de encontrar resposta à seguinte questão: Que Matemática ensinar à criança da Educação Infantil?

Trabalhar com o que tem sido discutido nos últimos anos em um evento específico, como o SHIAM, que tem em suas raízes na ação de incentivo ao relato das práticas dos professores, torna-se relevante na medida em que defendemos o posicionamento do professor reflexivo e de sua ação emancipatória quando este problematiza sua prática, característica possível ao escrever sobre o que desenvolve no cotidiano da carreira.

\footnotetext{
${ }^{3}$ Reconhecemos que existem outros eventos como, por exemplo: ENEM, EPEM entre outros, mas o SHIAM já aponta para a relevância das práticas desde o seu título, o que para nós implicitamente anuncia o seu caráter ideológico.
}

Tangram - Revista de Educação Matemática, Dourados - MS - v.3 n.1, pp. 18 - 45(2020) 


\section{Análise bibliométrica dos relatos de experiência sobre "Matemática na Educação Infantil" publicados no SHIAM (2013-2017)}

A relevância de tais reflexões reside ainda em, a partir da análise dos trabalhos, levantar possibilidades da abordagem das noções matemáticas, bem como quais métodos o professor pode recorrer para a realização desta tarefa. Para o direcionamento e operacionalização da proposta, elegeu-se a seguinte questão de pesquisa: Quais são os conteúdos matemáticos predominantes nos relatos de experiências publicados nos anais do SHIAM e quais tendências em Educação Matemática apresentam-se como eixo da organização das práticas?

Entre números, formas, gráficos, tabelas, grandezas e medidas: o que se ensinar "de" e "sobre" Matemática na infância

De acordo com Lorenzato (2008) no Brasil, por volta de 1970, houve uma intensificação da luta por maior valorização da Educação Infantil, pois muitos pais viam as instituições de atendimento à infância apenas como um lugar para que seus filhos pudessem ficar enquanto trabalhavam. Apesar dos avanços significativos em termos do reconhecimento do direito à educação da criança pequena via Constituição Federal (Brasil, 1988), bem como da inserção da Educação Infantil como primeira etapa da Educação Básica a partir da Lei de Diretrizes e Bases $n^{\circ} .9 .394$, de 20 de dezembro de 1996, em seu Art. 21, muitas famílias ainda têm o ideário de que o espaço/tempo dos locais que atendem as crianças são meramente assistencialista.

Cumpre salientar que a influência de agentes externos à instituição como, por exemplo, pais, políticos, médicos, psicólogos, demais profissionais da saúde sempre tiveram relações de poder para decisões importantes no campo da organização das práticas e rotinas das creches e pré-escolas. Em uma leitura histórica, não é preciso ir muito longe para compreender que o direito e acesso a uma Educação Infantil de qualidade ainda se faz em campo de "batalha" e em "duras" lutas com as quais professores travam, cotidianamente, ao proporem situações de aprendizagem com turmas, desde o berçário (Andrade, 2010). É neste contexto que emerge a necessidade de se trabalhar a Matemática com a criança pequena, por exemplo, uma vez que, esta ciência se faz presente em nossas vidas desde a mais tenra idade e ainda porque, enquanto responsáveis pelo desenvolvimento infantil, precisamos garantir os direitos de aprendizagens no período da infância.

Em defesa do ato de ensinar, neste trabalho de pesquisa temos um posicionamento que encara a figura do professor como a de um agente importante no processo de mediação entre Tangram - Revista de Educação Matemática, Dourados - MS - v.3 n.1, pp. 18 - 45(2020) 


\section{Análise bibliométrica dos relatos de experiência sobre "Matemática na Educação Infantil" publicados no SHIAM (2013-2017)}

a criança e o conhecimento matemático. Assim, uma proposta de ensino que respeite e garanta a aprendizagem precisa encarar o currículo como sendo "[...] um conjunto de práticas que buscam articular as experiências e os saberes das crianças com os conhecimentos que fazem parte do patrimônio cultural, artístico, científico e tecnológico" (Brasil, 2009, p. 06). Nesta perspectiva, as práticas são organizadas e efetivadas nas relações sociais que a criança, sujeito ativo na Educação Infantil, estabelece entre o adulto e com outras crianças e, por isso, articular o que esta já sabe sobre relações de quantidade, exploração do espaço, noções de grandezas e estimativa, constitui um caminho primordial para a sistematização de conhecimentos mais sólidos em termos do currículo matemático.

Autores como Lorenzato (2008) \& Kamii (2012) defendem que, antes do professor partir especificamente para o ensino dos campos matemáticos, existem procedimentos mentais básicos que representam papel importante, mais tarde, no aprender Matemática, por isso estes devem ser a base do processo, são eles: correspondência, comparação, classificação, sequenciação, seriação, inclusão e conservação.

Seguindo a linha de Lorenzato (2008), apresentamos a seguir uma síntese que define cada habilidade:

- Correspondência: é o ato de estabelecer a relação "um a um" como, por exemplo, um copo para cada pessoa; cada pé com seu sapato; uma carteira para cada criança, a ideia de correspondência envolve a criança nos mais variados contextos;

- Comparação: é o ato de estabelecer diferenças e semelhanças: "esta maçã é maior que aquela", "moro mais perto da escola do que ela", "temos o mesmo tamanho";

- Classificação: é o ato de agrupar objetos de acordo com suas semelhanças ou diferenças: organizar uma gaveta ou ainda, juntar os brinquedos e guardá-los em caixas;

- Sequenciação: ato de fazer suceder a cada elemento um outro sem considerar a ordem entre eles: chegada das crianças à sala de aula, escolher e apresentar os numerais no bingo;

- Seriação: ordenar uma sequência segundo um critério como, por exemplo, a fila de crianças do menor para o maior ou ainda a lista de chamada das crianças em ordem alfabética;

Tangram - Revista de Educação Matemática, Dourados - MS - v.3 n.1, pp. 18 - 45(2020) 


\section{Análise bibliométrica dos relatos de experiência sobre "Matemática na Educação Infantil" publicados no SHIAM (2013-2017)}

- Inclusão: ato de fazer abranger um conjunto por outro, como, incluir as ideias de melancia e de morangos em frutas, cachorro e gato em animais, meninos e meninas em crianças;

- Conservação: é o ato de perceber que a quantidade não depende da arrumação, forma ou posição como, um copo largo e outro estreito, ambos com a mesma quantidade de água, uma caixa com todas as faces retangulares, ora apoiadas sobre a face menor, ora sobre outra face, conserva a quantidade de lados, cantos e medidas (Lorenzato, 2008).

Ao incluir na rotina de Educação Infantil um trabalho frequente com tais procedimentos, o docente estará auxiliando o grupo de crianças e desenvolver o raciocínio do pensamento lógico-matemático, pois a partir desta prática a criança estará adquirindo noções basilares para consolidar conhecimentos numéricos, geométricos, das grandezas, estimativas, entre outros, aprendendo a classificar, ordenar, seriar, sequenciar, etc. (Kamii, 2012).

A partir do direcionamento inicial de como e por onde começar a explorar noções de natureza matemática com a criança precisamos compreender que os espaços da instituição constituem oportunidades ricas e promissoras para o desenvolvimento de propostas, nestes pode-se comparar, classificar, ordenar, incluir, contar objetos e/ou pessoas, sempre direcionando olhares para explicar a realidade. Essa vivência leva a criação de estratégias para resolver problemas diários, utilizando recursos próprios, questões essas que podem favorecer a elaboração de conhecimentos matemáticos (Brasil, 1998).

Smole, Diniz \& Cândido (2000, p.09), contribuem com a discussão ao afirmarem que:

\footnotetext{
Uma proposta de trabalho de matemática para a Educação Infantil deve encorajar a exploração de uma grande variedade de ideias matemáticas, não apenas numéricas, mas também aquela relativas à geometria, às medidas e às noções de estatísticas, de forma que as crianças desenvolvam e conservem com prazer uma curiosidade acerca da matemática, adquirindo diferentes formas de perceber a realidade.
}

Para que haja uma aprendizagem significativa que contribua para o desenvolvimento de uma visão atualizada da Matemática, cabe ao professor promover essa interação proporcionando contextos de aprendizagem estimulantes que desafiem as crianças e que lhes permitam, de acordo com as suas capacidades, ir avançando na caminhada de descoberta que é o conhecimento da Educação Matemática na infância e isso poderá auxiliar em atividades 


\section{Análise bibliométrica dos relatos de experiência sobre "Matemática na Educação Infantil" publicados no SHIAM (2013-2017)}

que ultrapassem o ordinário e cheguem ao extraordinário. No cotidiano das instituições infantis, Ciríaco (2012, p. 69), destaca que:

[...] para que a criança entenda, é preciso criar situações didáticas em que elas possam se envolver, discutir, brincar, analisar, explorando o pensamento matemático, e isto exige do professor de educação infantil uma prática diferenciada, com esquemas que priorizem recursos metodológicos que vão além da explanação no quadro negro e aplicação de exercícios de fixação dos conteúdos.

Desse modo, percebemos que há a necessidade de muitas mudanças, a começar pela concepção de criança e de infância que muitos professores em exercício têm, uma vez que, é a visão que se tem de um determinado objeto e/ou campo do conhecimento que direciona o agir frente a ele. Ensinar e aprender Matemática na Educação Infantil não ocorre fora deste contexto histórico e social que é o nascimento do sentimento de infância (Àries, 1978) e a construção/evolução deste conceito ao longo da História e da constituição das identidades das instituições que necessitam articular práticas de cuidado e educação com vista ao desenvolvimento pleno das crianças e isso ocorre, também, na natureza das tarefas matemáticas que o docente propõe.

Para este fim, embora já publicado há 20 anos, o Referencial Curricular Nacional para a Educação Infantil - Rcnei - (Brasil, 1998), tenta, apesar das críticas de seu conteúdo e organização (Haddad, 1998), orientar o trabalho do professor neste segmento.

De acordo com o Rcnei, os objetivos para se ensinar Matemática são:

- Desenvolver situações envolvendo matemática no cotidiano;

- Reconhecer os números;

- Desenvolver a contagem oral e escrita;

- Desenvolver noções de quantidade, medidas, espaço físico e formas;

- Estimular a autoconfiança e a capacidade de estratégias da criança ao se deparar com problemas e desafios (Brasil, 1998).

O documento destaca que à Educação Matemática com bebês e crianças pequenas, o ensino necessita explorar o tripé: "Números e sistema de numeração"; "Grandezas e medidas" e "Espaço e Forma" e, para a exploração destas noções, é importante integrá-los em uma proposta interdisciplinar, pois na Educação Infantil de acordo com Campos (2008) não deve existir “dias de aula de”. Ou seja, conforme já destacado no início desta seção, a visão de currículo envolve o conjunto de práticas das quais as crianças participam e, portanto,

Tangram - Revista de Educação Matemática, Dourados - MS - v.3 n.1, pp. 18 - 45(2020) 


\section{Análise bibliométrica dos relatos de experiência sobre "Matemática na Educação Infantil" publicados no SHIAM (2013-2017)}

não necessariamente, estas têm de ser estanques, fragmentando a Matemática da Linguagem Oral e Escrita, da Natureza e Sociedade, do Corpo e Movimento e da Arte.

A título de ilustração, as noções matemáticas referenciadas em Brasil (1998) são assim apresentadas:

- Números e sistema de numeração: envolve contagem, notação e escrita numérica e as operações matemáticas;

- Grandezas e medidas: exploração de diferentes procedimentos de comparação de grandezas, introdução às noções de medida de comprimento, peso, volume, marcação do tempo e experiências com dinheiro;

- Espaço e forma: explicitação e/ou representação da posição de pessoas e objetos, exploração e identificação de propriedades geométricas de objetos e figuras, representações bidimensionais e tridimensionais de objetos, identificação de pontos de referência e descrição de pequenos percursos e trajetos.

Tendo em vista a inclusão de atividades desta natureza, o Rcnei aponta que a organização da prática de ensino precisa ocorrer por meio da resolução de problemas, haja vista que “[...] as crianças estarão, consequentemente, desenvolvendo sua capacidade de analisar, sintetizar, inferir, formular hipótese, deduzir, refletir e argumentar" (Brasil, 1998, p. 212). De acordo com Lorenzato (2006) a abordagem das noções matemáticas com ideias de números/sistema de numeração, geometria e grandezas e medidas corresponde a uma proposta pedagógica que visa articular o tripé da aprendizagem de conceitos neste período da vida da criança. Contudo, embora os documentos não sinalizem possibilidades para a inclusão de habilidades estatísticas, probabilísticas e de combinatória, estas constituem caminhos promissores para a problematização de situações cotidianas no âmbito da rotina de Educação Infantil (Lopes, 2003).

Em seu dia a dia, a criança está em contato com inúmeras situações que precisam ser entendidas e solucionadas como, por exemplo, uma situação onde seja feita uma votação para saber qual é a brincadeira predileta, o livro de literatura que mais se gosta, profissões dos pais, entre outros, estas contribuem para que o professor possa organizar seu trabalho com a Matemática de maneira exploratória colocando o sujeito (criança) como protagonista de sua aprendizagem.

Tangram - Revista de Educação Matemática, Dourados - MS - v.3 n.1, pp. 18 - 45(2020) 


\title{
Análise bibliométrica dos relatos de experiência sobre "Matemática na Educação Infantil" publicados no SHIAM (2013-2017)
}

Segundo Lopes (2003, p. 16):

\begin{abstract}
Cada vez mais e mais rapidamente têm-se solicitado diferenciadas habilidades e competências Matemáticas dos cidadãos. Nesse sentido, acreditamos que o desenvolvimento do pensamento estatístico e probabilístico, que deve ser inserido no contexto escolar, possa apresentar significativas contribuições para a formação desde a infância.
\end{abstract}

Concordamos com Azevedo (2007, p. 07), quando a autora afirma que:

[...] não há um campo da Matemática mais importante que outro, e sim o equilíbrio entre eles contribui para a educação integral das crianças. É necessário ter consciência que a criança precisa desenvolver vários tipos de raciocínio, para que tenha ferramentas para resolver problemas e compreender as relações que se estabelecem em seu dia-a-dia.

Ao selecionar os conteúdos matemáticos, devemos levar em consideração as vivências e conhecimentos prévios da criança buscando aprimorá-los cada vez mais em uma perspectiva lúdico-exploratória. O desenvolvimento dos conceitos matemáticos está fortemente atrelado às experiências informais e pode ser representado de forma natural ao se utilizar a própria rotina, por exemplo.

Neste sentido, os educadores necessitam estar conscientes da importância de seu papel, que é permitir às crianças condições para que aprendam de forma considerável as noções matemáticas. Com o fazer matemático, explorando novas descobertas e se apropriando de novos conhecimentos que fazem parte do seu cotidiano, fazendo com que as aulas sejam momentos de reflexão de transformação na maneira de pensar, ver e viver a realidade, $o$ ato de ensinar Matemática torna-se uma ação natural e pacífica.

A importância da mediação e das situações lúdicas, por exemplo, não pode ser ignorada na busca de uma prática com a Educação Matemática na infância. Autores como Kishimoto (2010), Smole (2000) \& Santos (2000) consideram a atividade lúdica (jogo e/ou a brincadeira) são características essenciais para o trabalho com a criança pequena.

Acreditamos que as instituições de Educação Infantil devem construir um trabalho com caráter educativo-pedagógico, adequado que atenda às especificidades infantis, as quais a brincadeira torna-se elemento essencial. Desse modo, ser um profissional da Educação Infantil exige que o professor fomente novas práticas de ensino, com domínio de conteúdos e um pensamento diferente do professor que atua no Ensino Fundamental. Para tanto, deve se apropriar dos conceitos que fundamentam o ensino de modo que a prática educativa venha a favorecer a relação entre o cuidar, o educar e o brincar. As brincadeiras, para o aprendizado Tangram - Revista de Educação Matemática, Dourados - MS - v.3 n.1, pp. 18 - 45(2020) 


\section{Análise bibliométrica dos relatos de experiência sobre "Matemática na Educação Infantil" publicados no SHIAM (2013-2017)}

da Matemática, devem ser dirigidas e com finalidades, favorecendo assim o desenvolvendo de capacidades importantes tais como, a memorização, a imaginação, a noção de espaço, a percepção e a atenção.

O lúdico no ensino da Matemática, além de ser dinâmico, faz com que o grupo de crianças se sinta com maior prazer em aprender, pois elas se identificam com atividades que caracterizam-se como sendo um ambiente sem pressão por respostas certas, ou seja, brincando a criança aprende.

$\mathrm{Na}$ fase da Educação infantil, a criança ainda está desenvolvendo a capacidade de atenção, pois ela se dispersa com muita facilidade. As brincadeiras ajudam nesse processo, pois sente-se atraída por atividades voltadas para seu mundo. Além de ser um forte aliado do aprendizado, o lúdico proporciona maior interação criança/professor e criança/criança, não devendo ser encarado como uma competição, mas sim como uma forma divertida de descobrir e aprender.

A capacidade lúdica do professor é um processo que precisa ser pacientemente trabalhada. Ela não é imediatamente alcançada. O professor que, não gostando de brincar, esforça-se por fazê-lo, normalmente assume postura artificial facilmente identificada pelos alunos (Kishimoto, 1998, p. 122).

A prática do ensino lúdico exige a participação sincera, criativa, livre, promovendo a interação social e tendo em vista o forte compromisso de transformação e codificação do meio. O que muitos professores da Educação Infantil precisam entender é que o brincar é um meio real de desenvolvimento à aprendizagem para toda vida. Por meio do brincar a criança será capaz de aumentar e enriquecer a sua aprendizagem de forma natural.

Em síntese, a adoção do lúdico na Educação Infantil pode favorecer a aprendizagem matemática, uma vez que, brincar é tão sério para a criança quanto o trabalho é para o adulto (Smole, Diniz \& Cândido, 2000). Desse modo, as crianças serão incentivadas a encontrarem soluções, usarem a lógica, a capacidade de estratégia e a tomada de atitudes. Cabe ao professor oportunizar experiências com esses conceitos, sobretudo, respeitando o desenvolvimento cognitivo ao oportunizar acesso ao conhecimento matemático de forma exploratória para além de números, incorporando contextos de trabalho com a geometria, grandezas e medidas e noções de estatística, combinatório e probabilidade.

\section{Metodologia da pesquisa}

Tangram - Revista de Educação Matemática, Dourados - MS - v.3 n.1, pp. 18 - 45(2020) 


\section{Análise bibliométrica dos relatos de experiência sobre "Matemática na Educação Infantil" publicados no SHIAM (2013-2017)}

O estudo se inscreve no campo da pesquisa qualitativa, de caráter descritivo-analítico, em que adotamos a perspectiva bibliométrica. "O termo bibliometria é utilizado para quantificar os processos de comunicação escrita e, o emprego de indicadores bibliométricos para medir a produção científica" (Reveles \& Takahashi, 2007. p. 246). Esse tipo de pesquisa é uma importante ferramenta para a realização de mapeamentos da produção do conhecimento a partir de um levantamento de textos/artigos de uma determinada temática, neste caso de experiências com a Matemática no âmbito da Educação Infantil.

Para tanto, recorremos a uma proposta de estudo com foco de analisar a produção de relatos de experiências sobre a Educação Infantil presente nos trabalhos publicados nas edições do Seminário Nacional de História e Investigação de/em Aulas de MatemáticaSHIAM, nos anos de 2013, 2015 e 2017.

$\mathrm{Na}$ perspectiva de responder o foco investigativo, no período mencionado, pretendemos atingir os objetivos específicos e indicadores de análise mencionados no quadro abaixo:

Quadro 01: Relação entre objetivos específicos e indicadores de análise.

\begin{tabular}{|l|l|}
\hline \multicolumn{1}{|c|}{ OBJETIVOS } & $\begin{array}{l}\text { INDICADORES DE ANÁLISE DE } \\
\text { DADOS }\end{array}$ \\
\hline $\begin{array}{l}\text { Caracterizar como a Matemática na } \\
\text { Educação Infantil vem sendo abordada } \\
\text { nos trabalhos publicados no SHIAM; }\end{array}$ & $\begin{array}{l}\text { Tendências em Educação Matemática } \\
\text { apresentadas como eixo da } \\
\text { organização dos relatos presentes na } \\
\text { estruturação dos artigos. }\end{array}$ \\
\hline - Investigar quais são os conteúdos \\
$\begin{array}{l}\text { matemáticos predominantes nos relatos } \\
\text { de experiências publicados nos anais do }\end{array}$ & $\begin{array}{l}\text { Conteúdos específicos pertinentes ao } \\
\text { ensino da Matemática para crianças } \\
\text { pequenas; }\end{array}$ \\
\hline $\begin{array}{l}\text { SHIAM; } \\
\text { Áreas/conceitos matemáticos com } \\
\text { maior proporcionalidade de trabalho } \\
\text { dos professores. }\end{array}$ \\
$\begin{array}{l}\text { Levantar as contribuições dos relatos } \\
\text { prática processo de reflexão sobre a a dos autores. }\end{array}$ & $\begin{array}{l}\text { Indícios da reflexão a partir das } \\
\text { conclusões dos trabalhos analisados; } \\
\text { Impactos acerca da temática } \\
\text { (perspectivas e dificuldades). }\end{array}$ \\
\hline
\end{tabular}

Fonte: Os autores, 2018.

Para atender aos objetivos propostos no quadro, elencamos os anais do SHIAM (https://www.cempem.fe.unicamp.br/shiam/anais) como fonte direta de coleta de dados, uma vez que o referido evento reúne pesquisadores de todo Brasil, bem como diversos níveis e modalidades matemáticas. Este evento tem como objetivo, compartilhar, discutir e sistematizar experiências, propostas e investigações de/em aulas de matemática, desenvolvidas em diferentes localidades e regiões do Brasil, em todos os níveis de ensino, Tangram - Revista de Educação Matemática, Dourados - MS - v.3 n.1, pp. 18 - 45(2020) 


\section{Análise bibliométrica dos relatos de experiência sobre "Matemática na Educação Infantil" publicados no SHIAM (2013-2017)}

explicitando e problematizando os múltiplos sentidos e perspectivas das práticas de ensinar/aprender Matemática na escola básica.

O trabalho empírico deu-se com base na catalogação dos artigos a partir do contato com a produção. Para este fim, acessamos os anais das edições de 2013, 2015 e 2017 realizando, inicialmente, a leitura dos resumos para identificação se eram comunicações científicas e/ou relatos de experiência. Ao perceber o foco de cada texto, selecionamos os que se tratavam de relatos de experiência (foco desta investigação) e assim iniciamos a leitura na íntegra na busca dos que abordavam a Educação Infantil, especificamente.

A tabela 01 sintetiza o número de trabalhos encontrados nos anais:

\begin{tabular}{c|ccc} 
Ano & \multicolumn{2}{c}{$\begin{array}{c}\text { Tabela } 01-\text { Número de trabalhos por edição } \\
\text { Total de } \\
\text { comunicações }\end{array}$} & $\begin{array}{c}\text { (2013 a 2017). } \\
\text { Relatos de experiência geral } \\
\text { Relatos de experiência na } \\
\text { Educação Infantil }\end{array}$ \\
\hline $\mathbf{2 0 1 3}$ & 215 & 72 & 11 \\
$\mathbf{2 0 1 5}$ & 138 & 69 & 3 \\
$\mathbf{2 0 1 7}$ & 112 & 32 & - \\
\multicolumn{2}{|c|}{ Total geral Educação Infantil } \\
& \multicolumn{2}{c}{ Fonte: Os autores, 2018. }
\end{tabular}

O contato com os anais fez-nos constatar que na edição de 2013 foram publicados 215 (duzentos e quinze) trabalhos no total, sendo que 72 (setenta e dois) foram de relatos de experiência com a Matemática de forma geral, destes 11 (onze) referiam-se a Educação Infantil.

Como vimos, em 2015 havia 138 (cento e trinta e oito) textos publicados, sendo 69 (sessenta e nove) relatos de experiência e deste total 3 (três) eram na Educação Infantil.

No ano de 2017, foram publicados 112 (cento e doze) artigos, destes 32 (trinta e dois) correspondiam aos relatos de experiência gerais e não foram localizados textos com o foco na infância.

Em síntese, realizando o mapeamento nas edições do SHIAM, conforme ilustra o quadro, verificamos um total de 14 (catorze) trabalhos que enfatizaram a prática docente, ou seja, comunicaram "relatos de experiência". Em posse dos estudos, passamos a fase de leitura e análise crítica dos mesmos no sentido de tentar agrupá-los para que pudéssemos evidenciar qual assunto e/ou área dos campos matemáticos a serem desenvolvimentos na Educação Infantil apareceriam de forma mais abrangente, visando atender as expectativas iniciais da proposta originária desta investigação.

Tangram - Revista de Educação Matemática, Dourados - MS - v.3 n.1, pp. 18 - 45(2020) 


\section{Análise bibliométrica dos relatos de experiência sobre "Matemática na Educação Infantil" publicados no SHIAM (2013-2017)}

\section{Descrição e análise de dados}

A experiência direta de coleta de informações via anais do evento, trouxe o entendimento, ao que os dados indicam, de que a Educação Infantil é, aparentemente, pouco recorrente em textos que visam compartilhar experiências sobre atividades matemáticas com crianças. Ilustra essa afirmativa o fato de que dentre os 187 (100\%) artigos, 173 (93\%) são dos anos iniciais e finais do Ensino Fundamental, bem como de experiências no Ensino Superior em programas de iniciação à docência, resultados de intervenções de estágios na formação inicial de professores, relatos de ações de formação contínua no campo da Educação Matemática com o professor de Matemática e/ou o pedagogo.

Já no que se refere à Educação Infantil, identificou-se a presença de apenas 14 (7\%) da produção do conhecimento do SHIAM entre 2013 a 2017. Dentre o número dos textos que encontramos, temos a proporção da divisão da creche e pré-escola representadas no gráfico:

Gráfico 01: Tendência da produção do conhecimento dos relatos de experiências na creche e na pré-escola no SHIAM (2013-2017).

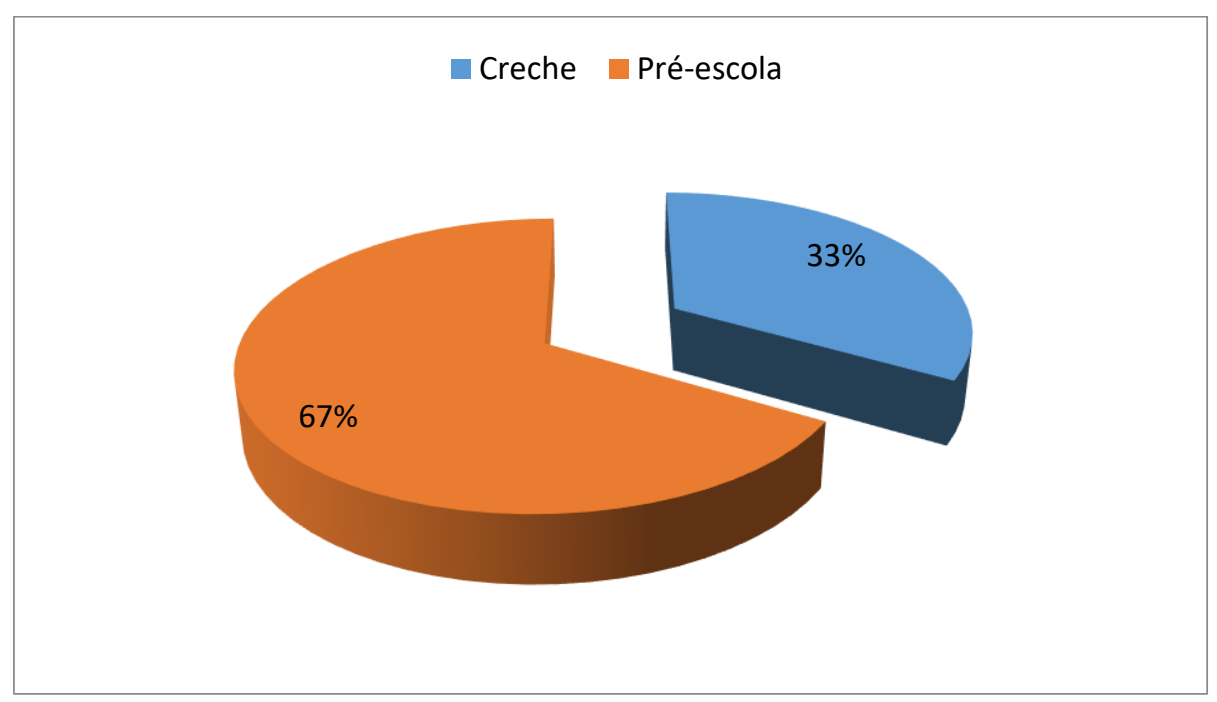

Fonte: Os autores, 2018.

Em termos de proporcionalidade das áreas do conhecimento matemático (números e sistema de numeração, espaço e forma, grandezas e medidas, estatística e probabilidade) verificou-se que houve empate entre números/sistema de numeração e o campo de espaço e forma, ao que indica o gráfico 02:

Tangram - Revista de Educação Matemática, Dourados - MS - v.3 n.1, pp. 18 - 45(2020) 


\section{Análise bibliométrica dos relatos de experiência sobre "Matemática na Educação Infantil" publicados no SHIAM (2013-2017)}

Gráfico 02: Predominância dos conceitos matemáticos nos relatos de experiência - SHIAM (2013-2017).

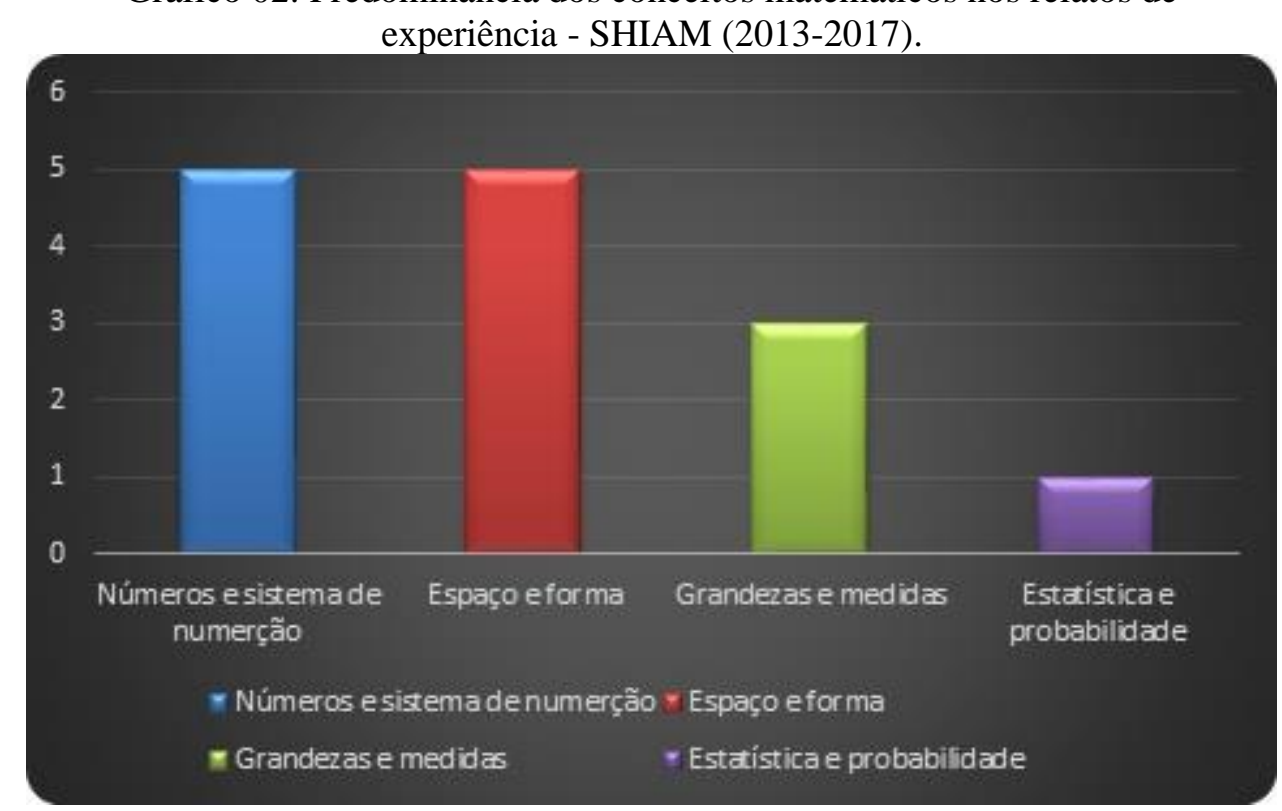

Fonte: Os autores, 2018.

Após a realização do levantamento, conforme retratado no gráfico acima, observou-se que parece haver uma tendência de práticas voltadas para atividades pré-numéricas e no campo das relações espaciais e das formas. Isso demonstra que há um cenário propício para metodologias de abordagem conceituais da Educação Matemática na Educação Infantil a partir de explorações dos conceitos por meio do brincar e da exploração livre, contemplando assim a participação ativa da criança, despertando a sua curiosidade e valorizando as suas potencialidades. Desse modo, o Referencial Curricular Nacional para Educação Infantil (Brasil, 1998) indica que os três blocos de conteúdos matemáticos destacados neste documento (números e sistema de numeração, grandezas e medidas e espaço e formas) devem ser trabalhados de forma igualitária e numa perspectiva interdisciplinar, haja vista que o desenvolvimento das noções matemáticas não deve estar centralizado apenas nos conhecimentos numéricos, como é recorrente de se ver nas salas de Educação Infantil.

Na apreciação das publicações, ao agrupar os relatos de 2013 no campo de "Números e sistema de numeração" encontramos: Carcanholo \& Oliveira (2013), Andricioli \& Azevedo (2013), Boas (2013), Graupner \& Silva (2013), totalizando 4 (quatro).

Tangram - Revista de Educação Matemática, Dourados - MS - v.3 n.1, pp. 18 - 45(2020) 


\section{Análise bibliométrica dos relatos de experiência sobre "Matemática na Educação Infantil" publicados no SHIAM (2013-2017)}

Carcanholo \& Oliveira (2013) desenvolveram um trabalho centrado na linguagem matemática com crianças de 5 anos de idade. Alguns objetivos do trabalho incluíram experiências de como desenvolver o conhecimento da função social do número, da diferenciação entre números e letras e do reconhecimento numérico em diversos espaços. Neste relato, evidencia-se a importância das diversas linguagens na Educação Infantil, nas quais a linguagem matemática recebe destaque ao trabalho docente. Para que esta seja desenvolvida, considerou-se o ensino numa vertente contextualizada, podendo assim ser denominada como alfabetização matemática.

Para os autores, este novo termo agrega a ideia de que para aprender Matemática no período que compreende a infância, é preciso que as crianças estejam diariamente cercadas por propostas e oportunidades que evoquem o uso da competência lógico-matemática, incorporando contextos do mundo real, com experiências e a linguagem natural infantil. A partir desta ideia central, discorreram-se ao longo deste trabalho, sugestões de atividades ou projetos que possam ser desenvolvidos com crianças de forma que a alfabetização matemática aconteça e promova o pensamento matemático, em uma vertente integradora e interessante, promovendo assim a aprendizagem e o desenvolvimento da turma em que as atividades ocorreram.

Andricioli \& Azevedo (2013) relataram atividades desenvolvidas por professoras atuantes na rede municipal de São Carlos - SP - que são integrantes do Grupo de Estudos Outros Olhares para a Matemática (GEOOM), vinculado a um projeto de extensão da Universidade Federal de São Carlos (UFSCar). No ambiente das discussões deste grupo colaborativo, foi decidido trabalhar o "Jogo dos Numerais" com uma turma de crianças com cinco e seis anos, pertencentes à sala de aula em que a primeira autora é regente. O material utilizado foram cartas com numerais de 1 a 5 .

A dinâmica do jogo ocorreu da seguinte forma: o jogo era em dupla, enquanto um dos jogadores jogava uma carta, no centro da dupla, em seguida, o outro jogador fazia sua jogada. Vencia a partida aquele que obtivesse a carta com maior numeral e, consequentemente, o jogo o que tiver mais cartas.

$\mathrm{O}$ objetivo principal foi proporcionar às crianças a oportunidade de reconhecer $\mathrm{e}$ comparar os numerais de um a cinco relacionando-os com suas quantidades de uma forma lúdica, o desafio de se adequar aos limites e regras e a socialização, assim como permitir que ocorresse a comparação entre conjuntos fora o ponto central das discussões e mediações da

Tangram - Revista de Educação Matemática, Dourados - MS - v.3 n.1, pp. 18 - 45(2020) 


\section{Análise bibliométrica dos relatos de experiência sobre "Matemática na Educação Infantil" publicados no SHIAM (2013-2017)}

professora com a turma. Avaliando a atividade, as crianças apresentaram muita dificuldade nas jogadas, não conseguiam identificar o ganhador, pois não relacionavam a carta maior com a menor e todos queriam vencer, foi necessária uma intervenção da professora e outra atividade foi proposta. Nessa nova atividade, receberam peças de brinquedos coloridas e deveriam separá-las de acordo com a solicitação por cor e quantidade como, por exemplo, era apresentado o numeral dois, deveriam separar duas peças amarelas. Aqui o direcionamento da proposta transcorreu sem muitos problemas, as autoras destacam que obtiveram sucesso, pois as crianças conseguiram associar os numerais às quantidades correspondentes.

Com isso, concluíram que a maior parte da sala começou a desenvolver estratégias de jogo como, por exemplo, o primeiro jogador iniciava sempre com a carta cinco porque "descobriu" que ganharia a jogada, dado que reforça a necessidade de intervenções que caminham no sentido de promover essa associação lógica, o que demanda tempo e mediações por parte do professor.

Boas (2013) apresenta um trabalho realizado em uma escola pública do município de Jundiaí-SP, com crianças da faixa etária de cinco anos. Trata-se de uma sequência de atividades realizadas com o jogo de boliche. O objetivo dessa comunicação foi apresentar o trabalho com o boliche em Matemática com ênfase às narrativas dos alunos. Na Educação Infantil, a aprendizagem de conceitos é motivadora para os alunos quando ela acontece por meio de jogos e brincadeiras, afirma Boas (2013). No direcionamento, foi possível abordar aspectos da contagem e das operações aritméticas iniciais como, por exemplo, a adição e a subtração.

O jogo do boliche possibilitou a construção de novos conhecimentos por meio de interações como os desafios e da escuta atenta às falas dos colegas sobre o que eles estão construindo em relação ao proposto. A análise do trabalho realizado com esta proposta possibilitou algumas reflexões, uma delas se refere à importância do trabalho com jogo na área de Matemática, visto que nessa fase da vida as crianças aprendem e se envolvem de forma mais ativa quando brincam, dependendo de como a brincadeira é mediada.

Graupner \& Silva (2013) propuseram, em seu artigo, a descrição e análise de uma prática pedagógica vivenciada por uma professora no desenvolvimento de uma atividade com crianças de 4 anos em uma escola pública do município de Capela do Alto (SP), da região metropolitana de Sorocaba. A proposta em questão teve como objetivos aproximar as Tangram - Revista de Educação Matemática, Dourados - MS - v.3 n.1, pp. 18 - 45(2020) 


\section{Análise bibliométrica dos relatos de experiência sobre "Matemática na Educação Infantil" publicados no SHIAM (2013-2017)}

crianças dos conceitos matemáticos necessários para a solução de problemas possibilitando uma vivência pré-numérica, representação gráfica dos algarismos e sua utilização na contagem de quantidades.

Foi possível perceber que a partir do contato com o objeto aprendido através de brincadeiras, as crianças foram capazes de formular hipóteses e resolver problemas de maneira natural, o que tornou a atividade significativa, pois tiveram a oportunidade de aprender de forma lúdica ao organizarem as informações e estratégias necessárias para a resolução, bem como a aproximação do conceito de número, identificando-o em diferentes contextos e funções para além do princípio da ordem e da cardinalidade.

Já os relatos de "Espaço e forma", trabalhos como os de Santos (2013), Amaral, Carisani \& Azevedo (2013), Pessa \& Azevedo (2013), Carisani, Depetri \& Azevedo (2013) e Ruffino \& Azevedo (2013), compuseram os anais do evento nesta edição.

O artigo de Santos (2013) faz referência ao uso de narrativas das aulas de Matemática desenvolvidas com um grupo de professoras de uma escola da rede municipal de Educação Infantil localizada na cidade de Jundiaí/SP que atende a faixa etária de 0 a 3 anos. As denominações das turmas são: berçário (para crianças até 1 ano), grupo 1 (acima de 1 ano), grupo 2 (acima de 2 anos) e grupo 3 (acima de 3 anos até 3 anos e 11 meses).

O foco desse relato centrou-se no trabalho colaborativo na escola, por meio da reflexão das imagens fotográficas produzidas pelas professoras nas aulas de Matemática apoiadas nas narrativas dos episódios de aula.

A intenção foi que após a produção das fotografias, o grupo passasse a pensar coletivamente no horário destinado à formação sobre as imagens das aulas e, juntamente com a produção das narrativas, pudessem dialogar com as suas práticas com base no compartilhamento dos registros.

Em relação ao material, a professora trouxe uma colcha e algumas bolinhas de plásticos. Segundo relato dela, a ideia era que as crianças buscassem estratégias para que as bolinhas não caíssem fora da colcha. Para este fim, seria preciso coordenar os movimentos e compreender os conceitos matemáticos de geometria como, por exemplo, noções espaciais de "fora" e "dentro", presentes na linguagem matemática.

Em termos de conclusão, evidencia-se, portanto, que esses instrumentos quando compartilhados no grupo podem favorecer o trabalho colaborativo e a reflexão sobre a

Tangram - Revista de Educação Matemática, Dourados - MS - v.3 n.1, pp. 18 - 45(2020) 


\section{Análise bibliométrica dos relatos de experiência sobre "Matemática na Educação Infantil" publicados no SHIAM (2013-2017)}

prática, uma vez que, ao fazerem isso, as professoras ampliaram o repertório didáticopedagógico e passaram a ter novas ideias sobre como direcionar o grupo de crianças.

Amaral, Carisani \& Azevedo (2013) relatam uma experiência que tiveram ao trabalhar noções envolvendo a geometria em uma turma de 25 crianças de 4 a 5 anos de um Centro Municipal de Educação Infantil na cidade de São Carlos/SP durante o primeiro semestre de 2013.

Pensou-se numa sequência de propostas que contemplasse a investigação das noções das crianças acerca do assunto, atividades de movimento e competências espaciais e dobraduras. A história do livro intitulado "Um redondo pode ser quadrado?", de Renato Canini, foi o norte para desenvolver a construção de formas.

As práticas desenvolvidas com as crianças objetivaram proporcionar o máximo possível de experiências com formas, vivenciando o espaço, reconhecendo-se nele, identificando outras imagens no espaço e descrevendo atributos definidores (lados, formas, tamanhos).

Como conclusão, as professoras enfatizam que inicialmente tiveram o pensamento de que o grupo de crianças teria dificuldades em descrever formas, localizá-las no espaço escolar ou ainda reconhecê-las em diversos campos de trabalho (sala de aula, pátio da escola, área externa escolar), mas que os resultados foram bastante satisfatórios, uma vez que a participação ativa da turma proporcionou o envolvimento nas atividades e interesse pelo tema (Amaral, Carisani \& Azevedo, 2013).

Pessa \& Azevedo (2013) tiveram como relato um artigo que descreve a experiência de um trabalho desenvolvido com 20 crianças de 3 a 4 anos de idade da rede pública de São Carlos/SP. A partir de estudos realizados sobre geometria no grupo GEOOM, o tema tomou foco para ser trabalhado em sala de aula.

O trabalho englobou atividades de exploração com o material concreto "Geoplano". As crianças desenharam figuras no Geoplano e, posteriormente, fizeram dois tipos de registro. O primeiro foi livre, desenharam como brincaram com o material. Num segundo momento, em uma folha com malha pontilhada, representaram algumas formas que fizeram no Geoplano. O objetivo foi colocá-las em contato com as formas geométricas de modo significativo, o trabalho não foi simplesmente o de nomear figuras, mas, sim, de entrar em contato com a geometria brincando, explorando, observando, fazendo trocas de conhecimento entre as crianças.

Tangram - Revista de Educação Matemática, Dourados - MS - v.3 n.1, pp. 18 - 45(2020) 


\section{Análise bibliométrica dos relatos de experiência sobre "Matemática na Educação Infantil" publicados no SHIAM (2013-2017)}

Para as autoras, em uma avaliação do que fora realizado, é possível perceber que o Geoplano possibilitou o desenvolvimento da imaginação da turma. Elas fizeram e desfizeram figuras planas e começaram a se habituar a ver figuras em diversas posições. Além disso, os registros foram aliados importantes no reconhecimento das características específicas de cada figura.

O relato de Carisani, Depetri \& Azevedo (2013), teve como objetivo descrever uma experiência em um Centro Municipal de Educação Infantil - CEMEI - em São Carlos/SP com 25 crianças de 5 e 6 anos. O interesse pelo assunto, bem como o desenvolvimento da aula surgiu a partir do estudo deste tema no Grupo de Estudo Outros Olhares para a Matemática - GEOOM - vinculado com um projeto de extensão da UFSCar, frequentado pelas professoras do CEMEI.

No decorrer da proposta, recorreu-se a materiais concretos na aula de Educação Física: linha movimento, cordas, bambolês, bastões e cones. Na sala foram utilizados dados com figuras geométricas, brinquedos e objetos diversos para a execução de brincadeiras e exploração das formas. Houve também o reconhecimento e comparação das características e atributos definidores das figuras geométricas encontradas nos objetos da sala, brinquedos e na face do dado.

Ao longo do processo, percebeu-se a participação das crianças para estabelecer relações envolvendo formas e posições. Observou-se que em situações cotidianas da rotina escolar, as crianças sempre retomavam ao tema, fazendo comparações, reconhecendo formas em objetos diversos dentro e fora da instituição e recorrendo a expressões e vocabulário específico ao que foi apreendido.

Em suma, as autoras concluem o relato afirmando que as crianças participaram ativamente das atividades, a partir de situações simples e também desafiadoras, colaborando para uma aprendizagem significativa e importante para o desenvolvimento infantil.

O último trabalho com a temática foi o de Ruffino \& Azevedo (2013) que discorrem sobre a experiência de pular corda com crianças de 5 a 6 anos de um Centro Municipal de Educação Infantil também em São Carlos/SP. Uma das autoras, como professora da turma, buscou trabalhar a percepção espaço temporal, movimento e consciência corporal. Este relato busca responder tais questões: como as crianças aprendem a pular corda? Como se dão as correlações entre espaço e tempo neste processo? Que procedimentos podem 


\section{Análise bibliométrica dos relatos de experiência sobre "Matemática na Educação Infantil" publicados no SHIAM (2013-2017)}

contribuir para este aprendizado? Que relações as crianças estabelecem entre si durante nas brincadeiras de pular corda? (Ruffino \& Azevedo, 2013).

$\mathrm{Na}$ análise deste artigo, foi possível perceber que, para as autoras, as ladainhas ${ }^{4}$ são grandes aliadas na marcação do tempo e que em sintonia com o movimento do corpo, as crianças conseguem realizar com sucesso a brincadeira. $\mathrm{O}$ aprendizado não foi fácil para toda a turma, mas, aos poucos, respeitando a voluntariedade e a frequência da brincadeira, todos começaram a realizar com êxito os pulos e, a partir disso, foram inseridos aos poucos desafios para que pulassem de formas diferentes.

A partir dessa experiência, foi possível trabalhar a contagem dos pulos e das ladainhas envolvidas na brincadeira, medidas com a noção de velocidade, tempo, altura, distância e geometria a partir da percepção espacial. Percebemos ainda que o trabalho com as ladainhas auxiliou no desenvolvimento das noções de espaço e tempo, além de permitir que as crianças percebessem sequências e regularidades. Isso ocorreu através da relação entre a letra, o ritmo da ladainha e a coordenação de pular corda.

Em relação a "Grandezas e medidas", localizamos apenas 1 trabalho nos anais do evento, sendo este de Souza, Azevedo \& Passos (2013).

Este trabalho também traz a experiência do GEOOM da UFSCar. Trata-se de um grupo colaborativo que tem como objetivo estudar, discutir e refletir sobre o conhecimento matemático construído desde a primeira infância.

O grupo tem-se mostrado um instrumento eficiente na formação continuada de professoras da Educação Infantil que atuam na rede municipal de educação de São Carlos/SP e também na formação inicial de alunos da UFSCar. Uma das experiências marcantes para a licencianda no grupo foi o estudo sobre a temática medida.

Com base nas discussões de textos sugeridos pela formadora, as professoras elaboraram práticas pedagógicas significativas para abordar a temática. Jogos e atividades de investigação possibilitaram que as crianças lidassem com medidas não padronizadas. Todos os participantes do grupo perceberam que o conceito de medida é bastante abrangente, além disso, puderam explorar diferentes procedimentos para comparar grandezas.

O Grupo de Estudos Outros Olhares para a Matemática se reuniam, quando do momento da escrita deste artigo, quinzenalmente a fim de alcançar seus objetivos. Nas reuniões, cada professora participante compartilha experiências vivenciadas em sala de aula para que haja

\footnotetext{
${ }^{4}$ Movimentos corporais da capoeira.

Tangram - Revista de Educação Matemática, Dourados - MS - v.3 n.1, pp. 18 - 45(2020)
} 


\section{Análise bibliométrica dos relatos de experiência sobre "Matemática na Educação Infantil" publicados no SHIAM (2013-2017)}

uma maior problematização dos fatos, discute textos sugeridos pela formadora na perspectiva de relacionar teoria e prática no espaço da Educação Infantil e relatam as atividades trabalhadas, além de participarem de discussões em ambiente virtual.

Como principal conclusão dessa vivência com o tema medidas no grupo, foi possível identificar que a prática colaborativa deste espaço proporcionou perceber a importância que um grupo de estudo tem, principalmente, devido às características deste como a colaboração, o compartilhamento, a discussão e a problematização das práticas pedagógicas que envolvem o conhecimento matemático.

No eixo "Tratamento da informação", foi localizado, em 2013, o artigo de Camargo (2013), que relata um projeto desenvolvido em salas de $2^{\mathrm{a}}$ fase da Educação Infantil (crianças de 5 anos) em uma escola municipal de Itatiba-SP. O referido projeto é de característica interdisciplinar denominado "Trânsito e Mobilidade Urbana" voltado às noções de estatística. Objetivou-se trabalhar noções deste campo dos conteúdos matemáticos dentro do eixo "Tratamento da Informação" do currículo municipal.

A atividade foi desenvolvida a partir de um tema de estudo e, portanto, dentro de um contexto significativo. Para tanto, utilizando-se barbante como recurso material e para a representação dos dados foi construído um gráfico de setores, algo não muito comum na Educação Infantil, mas que apresentou-se como importante via de estruturação das informações tratadas com a turma.

As crianças puderam observar o gráfico final e discutir os dados coletados, chegando à conclusão que é mais fácil ver o resultado pelo gráfico do que pela tabela, pois segundo elas pelo gráfico "não precisa saber o número, é só ver o tamanho" (Camargo, 2013).

Como principal conclusão, a autora relata que a atividade desenvolvida com os alunos, foi muito produtiva e rica na opinião do grupo: direção e professores, já que partiu de um projeto interdisciplinar e proporcionou aos alunos a aquisição de novos conhecimentos matemáticos através construção e apropriação do saber matemático, uma vez que puderam refletir e analisar informações, coletar, registrar e analisar dados, além de construir um registro formal e inédito para eles.

Os trabalhos de 2015 no campo de "Números e sistema de numeração" diminuíram substancialmente quando comparado com 2013. Nesta edição do SHIAM, encontramos apenas o texto de Ramalho (2015).

Tangram - Revista de Educação Matemática, Dourados - MS - v.3 n.1, pp. 18 - 45(2020) 


\section{Análise bibliométrica dos relatos de experiência sobre "Matemática na Educação Infantil" publicados no SHIAM (2013-2017)}

Nesta experiência, relata-se um projeto desenvolvido pela autora com o Grupo 2 crianças de 2 a 3 anos da Unidade de Atendimento à Criança - UAC/UFSCar, Campus de São Carlos durante o mês de março de 2015. O projeto partiu do interesse das crianças em querer descobrir o nome das cores e das formas presentes no seu dia a dia.

As experiências envolveram os dois eixos fundamentais da Educação Infantil que são as interações e a brincadeira. Com o que foi proposto, evidencia-se práticas do brincar com os papéis picados, com flores, folhas, com os objetos redondos e começaram a construir conhecimentos matemáticos fundamentais para seu desenvolvimento. Lidaram com as habilidades de classificação e comparação que mais tarde serão fundamentais para a construção do conceito de número. Além disso, lidaram com as formas geométricas em seu cotidiano.

A experiência vivenciada fez com que a autora refletisse sobre a execução de um projeto de trabalho, isto é, ele não garante o aprendizado total de noções e conceitos matemáticos em uma vivência só, mas sabemos que a frequência de experiências desse tipo pode garantir que conceitos matemáticos sejam formados pelas crianças, principalmente, o conceito de número, dado mais explorado no desenvolvimento das atividades em sala de aula.

Não encontramos textos/relatos especificamente sobre a "Espaço e forma" nesta edição. Já os de "Grandezas e medidas", trabalhos como os de Pessa \& Ramalho (2015), Nogueira, Lotério \& Ramalho (2015), compuseram os anais.

Pessa \& Ramalho (2015) descrevem uma atividade matemática vinculada à literatura infantil que teve como objetivo discutir com as crianças questões sobre medidas a partir da comparação do que é pequeno, médio e grande. Estudos realizados sobre literatura infantil em conexão com a Matemática no grupo GEOOM (Grupo de Estudo "Outros Olhares para a Matemática"), nos direcionou a história "Cabritos, Cabritões" que dava abertura para trabalharmos noções de medidas com as crianças. O trabalho foi desenvolvido com uma turma de fase 4 (crianças entre 3 e 4 anos de idade) do CEMEI "Vicente de Paulo Rocha Keppe” da cidade de São Carlos/SP, no ano de 2013, com 14 crianças que estavam presentes no dia em que a história foi trabalhada em conexão com a Educação Matemática.

A história já era de conhecimento da turma, mas, nessa experiência, foi apresentada de forma diferente através da caixa de contação de histórias. Na proposta, de dentro caixa saíram fantoches de palitos e um cenário com o qual as crianças se envolveram. Após a contação, foram levantados alguns questionamentos para as crianças, nos quais foram nítidas

Tangram - Revista de Educação Matemática, Dourados - MS - v.3 n.1, pp. 18 - 45(2020) 


\section{Análise bibliométrica dos relatos de experiência sobre "Matemática na Educação Infantil" publicados no SHIAM (2013-2017)}

as discussões sobre medidas, comparação de objetos do cotidiano deles e medida da altura da turma com barbante. Todos as atividades se fizeram a partir da referência de elementos de natureza matemática a partir da narrativa.

Nogueira, Lotério \& Ramalho (2015) exploram, em seu artigo, um trabalho com crianças da Educação Infantil de 4 a 5 anos (fase 5) do "CEMEI José de Campos Pereira" na cidade de São Carlos/SP. O projeto partiu da leitura do livro “Adivinha o Quanto Eu Te Amo?”, de Sam McBratney, a discussão de tamanhos apresentada pelo livro desencadeou curiosidades nas crianças em saber quem era a menor e a maior da turma.

A partir disso, as professoras questionaram sobre como poderiam provar quem era grande e quem era pequeno. Depois de muita discussão, resolveram pegar um barbante e medir as crianças e, ao comparar os pedaços de barbantes, concluíram qual era a criança maior e menor. Depois disso, se organizaram livremente e formaram uma fila seguindo a ordem do menor para o maior, a partir daí as professoras questionaram o grupo sobre a organização feita.

Em seguida, fizeram um registro na lousa parecido com um gráfico e as crianças notaram que as medidas, uma ao lado da outra, ficaram como uma "escada". A partir da atividade foi possível concluir que é importante propor situações problemas que façam as crianças realizarem medições. É possível apresentar a elas problemas práticos para que possam medir as coisas ou elas mesmas em unidades não convencionais e, depois, avançar para os instrumentos de unidades padrão convencionais de medida. Essa vivência fez com que as crianças refletissem sobre o conceito de medida, que é complexo, mas perceberam que as noções de "mais alto" e "mais baixo", "pequeno" e "grande" são noções que antecedem o ato de medir.

Em suma, foi possível perceber também que ao utilizar o livro infantil os professores podem provocar pensamentos matemáticos, ou seja, motivar o exercício do raciocínio lógico através de questionamentos ao longo da leitura. Assim, entendemos que a literatura pode ser usada como estímulo para ouvir, ler, pensar e registrar sobre Matemática.

A edição do SHIAM de 2017, ao fazermos a leitura e apreciação crítica dos artigos publicados, não identificamos nenhum relato de experiência na Educação Infantil, razão pela qual não incorporará a análise de dados desta investigação.

Compreendendo as "entrelinhas" da prática docente: o que se ensina de Matemática na Educação Infantil?

Tangram - Revista de Educação Matemática, Dourados - MS - v.3 n.1, pp. 18 - 45(2020) 


\section{Análise bibliométrica dos relatos de experiência sobre "Matemática na Educação Infantil" publicados no SHIAM (2013-2017)}

A aproximação com o objeto de estudo descrito neste trabalho, ao realizarmos a leitura dos 14 artigos que encontramos, possibilitou-nos fazer algumas inferências acerca dos dados angariados como, por exemplo, a predominância de relatos de experiências em turmas de pré-escola, a expressiva participação do Grupo de Estudos Outros Olhares para a Matemática (GEOOM) da UFSCar, uma vez que, quase todos os trabalhos desenvolvidos com o ensino de conteúdos matemáticos na Educação Infantil decorreram das experiências de suas integrantes.

Como podemos perceber, o que predomina nas práticas pedagógicas, de acordo com os relatos apresentados nos anais do SHIAM nas edições aqui analisadas, é a exploração de "Números e sistema de numeração", empatado com "Espaço e forma", seguido de "Grandezas e medidas", tendo a menor incidência no campo da "Estatística e probabilidade". De modo geral, houve pouca referência à creche, o que implicitamente pode levar à crença de que parece, ao que os dados indicam, não se ter muita clareza sobre o que e como ensinar Matemática com crianças menores de 3 anos, ou seja, pertencentes à creche.

Contudo, devemos ressaltar que é importante e necessário que as crianças, desde pequeninas, tenham experiências de natureza matemática. Cumpre salientar, nesta perspectiva, que trabalhar Matemática, desde a mais tenra infância, implica, não necessariamente, um ensino sistemático de números, medidas, formas e noções de estatística/probabilidade. Antes, como vimos no referencial teórico, temos noções ligadas aos procedimentos mentais básicos como, por exemplo, ordenação, seriação, classificação, inclusão, entre outros, conforme nos coloca Lorenzato (2006). Assim, o que queremos dizer é que, se olharmos para o ensino da Matemática, na creche com uma perspectiva conteudista, pouco poderemos de fato contribuir com o desenvolvimento e aprendizagem das crianças, mas se tivermos "outros olhares" voltados para o pensamento lógico-matemático, poderemos, então, possibilitar o acesso ao conhecimento matemático.

$\mathrm{Na}$ nossa interpretação, talvez uma grande dúvida dos educadores das creches e préescolas ainda seja de que maneira, especificamente, esses conteúdos podem ser abordados na infância para que as crianças possam construir seus conhecimentos de forma eficiente e segura tomando-os como bases para conhecimentos futuros da própria disciplina, permitindo a autonomia da criança na sua vida em sociedade.

Tangram - Revista de Educação Matemática, Dourados - MS - v.3 n.1, pp. 18 - 45(2020) 


\section{Análise bibliométrica dos relatos de experiência sobre "Matemática na Educação Infantil" publicados no SHIAM (2013-2017)}

As experiências e vivências, características da infância, nos levam a crer que são inúmeras as possibilidades para se trabalhar Matemática com crianças tanto da creche quanto de idade pré-escolar, desde que o professor esteja atento e favoreça a participação ativa delas no processo.

\section{Considerações finais}

Neste artigo, tivemos como intenção analisar a produção de relatos de experiências sobre a Educação Infantil presente nos trabalhos publicados nas edições do Seminário Nacional de História e Investigação de/em Aulas de Matemática-SHIAM. Para este fim, levantamos os textos apresentados nas três últimas edições do evento (2013, 2015 e 2017).

Em relação ao processo de caracterização de como as práticas de ensino foram propostas nos relatos, observou-se que prevalece uma maior incidência na pré-escola. Essa recorrência, possivelmente se dê porque a criança dessa faixa etária está próxima a ingressar no Ensino Fundamental e na visão do docente, esse seja o momento de introduzir tais conteúdos numa perspectiva preparatória para ingresso no $1^{\circ}$ ano, o que não é objetivo da Educação Infantil. A apreciação das publicações trouxe-nos o dado de que os relatos de experiências com Matemática na creche são quase escassos.

Verificamos, a partir dos dados apresentados, que a maior parte das atividades parecem recair no campo numérico, empatando com espaço e forma, isso demonstra que embora haja uma mudança significativa nas práticas pedagógicas com a Matemática na infância ainda apresentam uma natureza fragilizada em termos de desenvolvimento de propostas que possibilitem o pensamento e autonomia infantil, uma vez que, tanto os documentos oficiais como, por exemplo, o Rcnei (1998) e a literatura especializada na temática indicam um trabalho que coloque a criança frente a experiências também com Grandezas e Medidas e noções de Estatística e Probabilidade.

A análise que fazemos, dos resultados obtidos na investigação, é que existe uma concepção de Educação Matemática na infância que precisa ser repensada e problematizada. Nesse sentido, os dados demonstram a necessidade de uma formação de professores que contribua para uma aprendizagem significativa, de forma a privilegiar a formação integral da criança, bem como a valorização da infância ao aprender e ensinar noções matemáticas

Tangram - Revista de Educação Matemática, Dourados - MS - v.3 n.1, pp. 18 - 45(2020) 


\section{Análise bibliométrica dos relatos de experiência sobre "Matemática na Educação Infantil" publicados no SHIAM (2013-2017)}

que podem ser exploradas a partir das vivências como ponto de partida para o trabalho docente.

A docência em Matemática na Educação Infantil vem se apresentando com dificuldade em associar o que se aprende sobre as recomendações para o ensino de conteúdos matemáticos nas instituições formadoras e as realidades presentes nas turmas de creches e pré-escolas, o que demonstra a importância de ressignificar o processo formativo. No entanto, de modo geral, existem avanços significativos nas atitudes das professoras quando estas participam de trabalhos colaborativos, como foi o caso do GEOOM da Universidade Federal de São Carlos - UFSCar, grupo que destacou-se, sobremaneira, na produção do conhecimento "de" e "sobre” Educação Matemática com a criança pequena.

Em síntese, com a conclusão deste estudo, podemos afirmar que o contributo da investigação reside no fato de que pudemos destacar variadas possibilidades da abordagem das noções matemáticas e discutir as perspectivas presentes na Educação Infantil, temos ainda diversas problematizações a serem pensadas, não findando aqui o desejo de investir e continuar no caminho da pesquisa sobre o ensino, característica que nos acompanha no cotidiano de nossas profissões seja na docência na Educação Básica, seja na docência no Ensino Superior.

\section{Referências}

Andrade, Lucimary Bernabé Pedrosa de. (2010). Educação infantil: discurso, legislação e práticas institucionais. São Paulo: Editora UNESP; São Paulo: Cultura Acadêmica.

Andricioli, Ana Carolina; Azevedo, Priscila Domingues de. (2012). Jogo dos numerais: aprendendo matemática através da brincadeira. In: Anais do IV Seminário Nacional de Histórias e Investigações delem Aulas de Matemática. Campinas, SP. Recuperado de: https://sites.google.com/site/anaisdoivsnhiam/historias-de-aulas-de-matematica, Acessado em: 22, mai. 2018.

Amaral, Dalice Alves Rapouzeiro do; Azevedo, Priscila Domingues de; Carisani, Andrea Cristina. Geometria na Educação Infantil. (2013). In: Anais do IV Seminário Nacional de Histórias e Investigações delem Aulas de Matemática. Campinas, SP. Recuperado de: https://sites.google.com/site/anaisdoivsnhiam/historias-de-aulas-de-matematica, Acessado em: 22, mai. 2018.

Ariès, Philippe. (1978). História social da infância e da família. Tradução: D. Flaksman. Rio de Janeiro: LCT.

Azevedo, Priscila Domingues de. (2009). As concepções de professores da Educação Infantil sobre a matemática. In: Anais do $17^{\circ}$ Congresso de Leitura do Brasil, Campinas/SP: ALB, 2009. v. 1. p. 1-12. Recuperado de: http://alb.org.br/arquivo-

Tangram - Revista de Educação Matemática, Dourados - MS - v.3 n.1, pp. 18 - 45(2020) 


\section{Análise bibliométrica dos relatos de experiência sobre "Matemática na Educação Infantil" publicados no SHIAM (2013-2017)}

morto/edicoes_anteriores/anais17/txtcompletos/sem07/COLE_4128.pdf, Acessado em: 29, mai. 2018.

Azevedo, Priscila Domingues de. (2007). Os fundamentos da prática de ensino de Matemática de professores da Educação Infantil Municipal de Presidente Prudente/SP e a formação docente. Dissertação (Mestrado em Educação). Faculdade de Ciências e Tecnologia da Universidade Estadual Paulista, FCT/UNESP de Presidente Prudente, $245 \mathrm{p}$.

Azevedo, Priscila Domingues de; Souza, Talita Fernanda de; Passos, Cármen Lúcia Brancaglion. (2013). Uma experiência de formação de professores no grupo de estudo outros olhares para a matemática. In: Anais do IV Seminário Nacional de Histórias e Investigações delem Aulas de Matemática. Campinas, SP. Recuperado de: https://sites.google.com/site/anaisdoivsnhiam/apresentacao, Acessado em: 22, mai. 2018.

Azevedo, Priscila Domingues de.

Carisani, Andrea Cristina.

Depetri, Sandra Regina de Rizzo.

Geometria na educação infantil: relato de uma abordagem lúdica. In: Anais do IV Seminário Nacional de Histórias e Investigações delem Aulas de Matemática. Campinas, SP. Recuperado de: https://sites.google.com/site/anaisdoivsnhiam/historiasde-aulas-de-matematica, Acessado em: 22, mai. 2018.

Azevedo, Priscila Domingues de; Ruffino, Sandra Fagionato. (2013). Pulando corda, conhecendo as possibilidades do corpo e aprendendo na educação infantil. In: IV Seminário Nacional de Histórias e Investigações delem Aulas de Matemática. Campinas, SP. Recuperado de: https://sites.google.com/site/anaisdoivsnhiam/historiasde-aulas-de-matematica, Acessado em: 22, mai. 2018.

Azevedo, Priscila Domingues de; Pessa, Jussara. (2013). Trabalhando com o Geoplano na Educação Infantil. In: Anais do IV Seminário Nacional de Histórias e Investigações delem Aulas de Matemática. Campinas, SP. Recuperado de: https://sites.google.com/site/anaisdoivsnhiam/historias-de-aulas-de-matematica, Acessado em: 22, mai. 2018.

Boas, Selma Nascimento Vilas. (2013). Jogo e narrativas de criança nas aulas de Matemática. In: Anais do IV Seminário Nacional de Histórias e Investigações delem Aulas de Matemática. Campinas, SP. Recuperado de: https://sites.google.com/site/anaisdoivsnhiam/historias-de-aulas-de-matematica, Acessado em: 22, mai. 2018.

Brasil. (1996). Lei de Diretrizes e Bases Nacionais para a Educação Básica. Lei nº 9.394/96. 20 de dezembro de 1996.

Brasil. (2009). Revisão das Diretrizes Curriculares Nacionais para a Educação Infantil. Parecer Homologado Despacho do Ministro, publicado no D.O.U. de 9/12/2009, Seção 1, pp- 14. Recuperado de: http://portal.mec.gov.br/dmdocuments/pceb020_09.pdf, Acessado em: 21, mai. 2018.

Tangram - Revista de Educação Matemática, Dourados - MS - v.3 n.1, pp. 18 - 45(2020) 


\section{Análise bibliométrica dos relatos de experiência sobre "Matemática na Educação Infantil” publicados no SHIAM (2013-2017)}

Brasil. (1988). Constituição da República Federativa do Brasil de 1988. Recuperado de: http://www.planalto.gov.br/ccivil_03/constituicao/constituicaocompilado.htm, Acessado em: 21, mai. 2018.

Brasil. (1998). Ministério da Educação. Referencial Curricular Nacional para a Educação Infantil: Conhecimento de Mundo. Brasília: Ministério da Educação Secretaria de Educação Fundamental.

Camargo, Giancarla Giovanelli de. (2013). Gráfico de setores: uma possibilidade de trabalho na Educação Infantil. In: Anais do IV Seminário Nacional de Histórias e Investigações delem Aulas de Matemática. Campinas, SP. Recuperado de: https://sites.google.com/site/anaisdoivsnhiam/historias-de-aulas-de-matematica,

Acessado em: 22, mai. 2018.

Campos, Maria Malta. (2008). Educar crianças pequenas: em busca de um novo perfil de professor. Retratos da Escola, Brasília, v. 2, p. 121-131, jan./dez. Recuperado de: http://retratosdaescola.emnuvens.com.br/rde/article/view/130/232, Acessado em: 06, abr. 2018.

Carcanholo, Flávia Pimenta de Souza; Oliveira, Guilherme Saramago de. (2013). A Educação Matemática na escola: contribuições para a aprendizagem das crianças na Educação Infantil. In: Anais do IV Seminário Nacional de Histórias e Investigações delem Aulas de Matemática. Campinas, SP. Recuperado de: https://sites.google.com/site/anaisdoivsnhiam/historias-de-aulas-de-matematica,

Acessado em: 22, mai. 2018.

Ciríaco, Klinger Teodoro. (2012). Conhecimentos e práticas de professores que ensinam Matemática na infância e suas relações com ampliação do Ensino fundamental. Dissertação (Mestrado em Educação). Faculdade de Ciências e Tecnologia da Universidade Estadual Paulista, FCT/UNESP, Presidente Prudente-SP. 334 p.

Graupner, Marli de Carvalho. Silva, Jaqueline Ferreira da. (2013). Utilizando os jogos para o ensino de matemática na Educação infantil. In: Anais do IV Seminário Nacional de Histórias e Investigações delem Aulas de Matemática. Campinas, SP. Recuperado de: https://sites.google.com/site/anaisdoivsnhiam/historias-de-aulas-de-matematica,

Acessado em: 22, mai. 2018.

Haddad, Lenira. (1998). O referencial curricular nacional para a Educação Infantil no contexto das políticas para a infância: uma apreciação crítica. Caxambú: In: Anais da Associação Nacional de Pesquisa e Pós-graduação em Educação. ANPEd.

Kamii, Constance. (2012). A criança e o número: implicações educacionais da teoria de Piaget para a atuação com escolares de 4 a 6 anos. $39^{\circ}$ ed.Campinas, SP: Papirus.

Kishimoto, Tizuko Morchida. (2000). Jogos, brinquedos, brincadeiras e educação. 4. ed. São Paulo: Cortez.

Lopes, Celi Ap. Espasandin. (2003). O conhecimento profissional dos professores e suas relações com estatística e probabilidade na educação infantil. Tese (Doutorado em Educação). Faculdade de Educação, Universidade Estadual de Campinas, UNICAMP, Campinas. 290 p.

Tangram - Revista de Educação Matemática, Dourados - MS - v.3 n.1, pp. 18 - 45(2020) 


\section{Análise bibliométrica dos relatos de experiência sobre "Matemática na Educação Infantil" publicados no SHIAM (2013-2017)}

Lopes, Celi Aparecida Espasandin. Moura, Ana Regina Lanner de. (2003). As crianças e as ideias de número, espaço, formas, representações gráficas, estimativa e acaso. Campinas, SP: Graf. FE/UNICAMPI; CEMPEM.

Lorenzato, Sérgio. (2008). Educação Infantil e a percepção da matemática. $2^{\circ}$. ed. rev. E ampliada-Campinas. SP: Autores Associados.

Nogueira, Karina Falchione. Lotério; Fabiana Varandas. Ramalho; Priscila Domingues de Azevedo. (2015). A literatura infantil e as noções de medida: uma experiência com crianças a partir do livro "Adivinha o quanto eu te amo". In: Anais do V Seminário Nacional de Histórias e Investigações delem Aulas de Matemática. Campinas, SP. Recuperado de: https://www.cempem.fe.unicamp.br/sites/www.cempem.fe.unicamp.br/files/anais_shi am-v3.invau.pdf, Acessado em: 22, mai. 2018.

Pessa, Jussara. Ramalho, Priscila Domingues de Azevedo. (2015). Literatura infantil e Matemática - uma conexão possível! In: Anais do V Seminário Nacional de Histórias e Investigações delem Aulas de Matemática. Campinas, SP. Recuperado de: https://www.cempem.fe.unicamp.br/sites/www.cempem.fe.unicamp.br/files/anais_shi am-v2.hisau.pdf, Acessado em: 21, mai. 2018.

Ramalho; Priscila Domingues de Azevedo. (2015). A literatura infantil em conexão com a Matemática: uma experiência com o livro "Clact, Clact, Clac". In: Anais do V Seminário Nacional de Histórias e Investigações delem Aulas de Matemática. Campinas, SP. Recuperado de: https://www.cempem.fe.unicamp.br/sites/www.cempem.fe.unicamp.br/files/anais_shi am-v3.invau.pdf, Acessado em: 21, mai. 2018.

Reveles, Audrey Garcia. Takahashi, Regina Toshie. (2007). Educação em saúde ao ostomizado: um estudo bibliométrico. Rev Esc Enferm USP; 41(2):245-50. Recuperado de: http://www.scielo.br/pdf/reeusp/v41n2/09.pdf, Acessado em: 20, fev. 2018.

Santos, Santa Marli Pires dos. (2000). Brinquedoteca: a criança, o adulto e o lúdico. Petrópolis: Vozes.

Smole, Kátia Cristina Stocco. (2003). A Matemática na Educação Infantil: a teoria das inteligências múltiplas na prática escolar. Porto Alegre: Artmed.

Smole, Kática Cristina Stocco. Diniz, Maria Ignêz. Cândido, Patrícia. (2000). Brincadeiras infantis nas aulas de Matemática. Porto Alegre: Artmed.

Enviado:05/03/2020

Aceito: $28 / 03 / 2020$

Tangram - Revista de Educação Matemática, Dourados - MS - v.3 n.1, pp. 18 - 45(2020) 